\title{
Sellar Masses: An Epidemiological Study
}

\author{
Khaled Al-Dahmani, Syed Mohammad, Fatima Imran, Chris Theriault, \\ Steve Doucette, Deborah Zwicker, Churn-Ern Yip, David B. Clarke, Syed Ali Imran
}

\begin{abstract}
Background: Sellar masses (SM) are mostly benign growths of pituitary or nonpituitary origin that are increasingly encountered in clinical practice. To date, no comprehensive population-based study has reported the epidemiology of SM from North America. Aim: To determine the epidemiology of SM in the province of Nova Scotia, Canada. Methods: Data from all pituitary-related referrals within the province were prospectively collected in interlinked computerized registries starting in November 2005. We conducted a retrospective analysis on all patients with SM seen within the province between November 2005 and December 2013. Results: A total of 1107 patients were identified, of which 1005 were alive and residing within the province. The mean age at presentation was $44.6 \pm 18$ years, with an overall female preponderance $(62 \%)$ and a population prevalence rate of $0.1 \%$. Of patients with SM, $837(83 \%)$ had pituitary adenomas and $168(17 \%)$ had nonpituitary lesions. The relative prevalence and standardized incidence ratio, respectively, of various SM were: nonfunctioning adenomas (38.4\%; 2.34), prolactinomas (34.3\%; 2.22), Rathke's cyst (6.5\%; 0.5), growth hormone-secreting adenomas (6.5\%; 0.3), craniopharyngiomas (4.5\%; 0.2), adrenocorticotropic hormonesecreting adenomas $(3.8 \% ; 0.2)$, meningiomas $(1.9 \%)$, and others $(3.9 \% ; 0.21)$. At presentation, $526(52.3 \%)$ had masses $\geq 1 \mathrm{~cm}, 318(31.6 \%)$ at $<1 \mathrm{~cm}$, and $11(1.1 \%)$ had functioning pituitary adenomas without discernible tumor, whereas tumor size data were unavailable in 150 (14.9\%) patients. The specific pathologies and their most common presenting features were: nonfunctioning adenoma (incidental, headaches, and vision loss), prolactinomas (galactorrhea, menstrual irregularity, and headache), growth hormone-secreting adenomas (enlarging extremities and sweating), adrenocorticotropic hormone-secreting adenoma (easy bruising, muscle wasting, and weight gain) and nonpituitary lesions (incidental, headaches, and vision problems). Secondary hormonal deficiencies were common, ranging from 19.6\% to 65.7\%; secondary hypogonadism, hypothyroidism, and growth hormone deficiencies constituted the majority of these abnormalities. Conclusions: This is the largest North American study to date to assess the epidemiology of SM in a large stable population. Given their significant prevalence in the general population, more studies are needed to evaluate the natural history of these masses and to help allocate appropriate resources for their management.
\end{abstract}

RÉSUMÉ: Masses de la selle turcique : une étude épidémiologique. Contexte: Les masses de la selle turcique (MST) sont pour la plupart des tumeurs bénignes d'origine pituitaire ou non pituitaire, qui sont de plus en plus souvent identifiées en pratique clinique. À ce jour, aucune étude détaillée de population n'a été rapportée sur l'épidémiologie des MST en Amérique du Nord. Objectif: Le but de l'étude était de caractériser l'épidémiologie des MST dans une province canadienne, la Nouvelle-Écosse. Méthode: Les données de toutes les consultations concernant un trouble pituitaire depuis novembre 2005 ont été recueillies prospectivement dans cette province dans des banques de données informatiques inter-reliées. Nous avons effectué une analyse rétrospective des données de tous les patients de cette province atteints d'une MST entre novembre 2005 et décembre 2013. Résultats: Mille cent sept patients ont été identifiés dont 1005 étaient vivants et demeuraient dans cette province. L'âge moyen des patients au moment de la consultation pour une MST était de 44,6 \pm 18 ans et $62 \%$ étaient des femmes. Le taux de prévalence dans cette population était de $0,1 \%$. Parmi les patients présentant une MST, 837 patients (83\%) étaient porteurs d'un adénome pituitaire et 168 patients (17\%) présentaient des lésions non pituitaires. La prévalence relative et le rapport d'incidence standardisé de différentes MST s'établissaient comme suit: des adénomes non fonctionnels $(38,4 \% ; 2,34)$, des prolactinomes $(34,3 \%$; 2,22), des kystes de Rathke $(6,5 \%$; 0,5), des adénomes secrétant de l'hormone de croissance $(6,5 \% ; 0,3)$, des craniopharyngiomes $(4,5 \% ; 0,2)$, des adénomes secrétant de l'hormone corticotrope (3,8\%; 0,2), des méningiomes $(1,9 \%)$ ainsi que des tumeurs d'autre nature $(3,9 \% ; 0,21)$. Au moment de la consultation initiale, 526 patients $(52,3 \%)$ présentaient une masse de $\geq 1 \mathrm{~cm}, 318(31,6 \%)$ une masse $<1 \mathrm{~cm}$ et $11(1,1 \%)$ avaient un adénome pituitaire fonctionnel sans qu'une tumeur ne soit décelable. Les données sur la taille de la tumeur présente chez 150 patients (14,9\%) n'étaient pas disponibles. Voici les pathologies spécifiques rencontrées ainsi que leur symptomatologie la plus fréquente au moment de la consultation initiale : un adénome non-fonctionnel (découverte fortuite, céphalées et perte de vision), un prolactinome (galactorrhée, irrégularité menstruelle, céphalée), un adénome secrétant de l'hormone de croissance (hypertrophie des extrémités et sudation), un adénome secrétant de l'hormone corticotrope (ecchymoses, perte de masse musculaire et gain pondéral) et une lésion non pituitaire (découverte fortuite, céphalées et troubles visuels). Les déficits hormonaux secondaires étaient fréquents, soit chez $19,6 \%$ à $65,7 \%$ des patients, et consistaient surtout en un hypogonadisme secondaire, une hypothyroïdie ou un déficit de l'hormone de croissance. Conclusions: Notre étude est la plus grande étude nord-américaine à ce jour évaluant l'épidémiologie des MST dans une grande population stable. Étant donné leur prévalence importante dans la population en général, il faudra procéder à des études supplémentaires pour établir l'histoire naturelle de ces MST et pour favoriser l'allocation de ressources adéquates pour leur prise en charge.

Keywords: pituitary adenomas, pituitary tumo

doi:10.1017/cjn.2015.301

Can J Neurol Sci. 2016; 43: 291-297

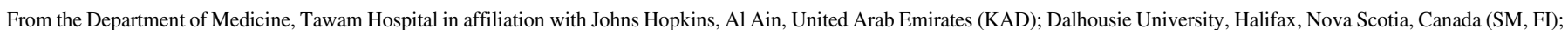

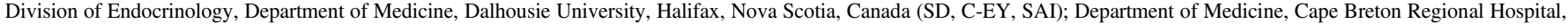

Sydney, Nova Scotia, Canada (DZ); Division of Neurosurgery, Dalhousie University, Halifax, Nova Scotia, Canada (DBC).

Received March 31, 2015. Final Revisions Submitted July 14, 2015.

Correspondence to: S. A. Imran, Division of Endocrinology and Metabolism, Dalhousie University, Halifax, NS, Canada B3H 2Y9. Email: simran @ dal.ca. 
Sellar masses (SM) are mostly benign growths of pituitary or nonpituitary origin that are increasingly encountered in clinical practice. They constitute approximately $14 \%$ to $18 \%$ of all brain tumors. $^{1,2}$ These tumors may be found incidentally during brain imaging or may present with symptoms of mass effect or profound hormonal abnormalities, resulting in significant morbidity.

Despite their prevalence and clinical importance, relatively few population-based studies, primarily from Europe and Asia, have reported on SM incidence, ${ }^{3,4}$ prevalence, ${ }^{5-7}$ or both. ${ }^{8}$ Data from North America are particularly scarce and are primarily derived from brain tumor registries, ${ }^{9}$ autopsy, or radiological studies. ${ }^{10-12}$ Furthermore, these studies have primarily focused on pituitary adenomas and excluded other sellar and parasellar tumors. To date, no comprehensive population-based study has reported the epidemiology of SM from North America.

We conducted a population-based study to assess the epidemiological trends of clinically manifesting SM in Nova Scotia, Canada. Nova Scotia is a major Atlantic province with a steady population of almost 1 million based on the 2011 census report. Neurosurgery services are only available at Dalhousie University, Halifax, Nova Scotia, which is the major tertiary care referral center, whereas endocrinology services are available either at Dalhousie University or Sydney, Cape Breton, which is a secondary referral center in northern Nova Scotia. All patients with SM are referred to either of the two endocrine centers (Halifax and Sydney) or the neurosurgery center (Halifax). No additional health care in either endocrinology or neurosurgery exists outside these centers in the province. Therefore, this provincial health care setting provides an ideal place to conduct our study, which aims to assess the incidence and the prevalence of SM in a population of almost 1 million.

\section{Methods ANd Materials}

\section{Study Design and Methods}

Data from both referral centers (Halifax and Cape Breton), which constitute all pituitary-related referrals within the province, are prospectively collected in a computerized interlinked registry. These include the Halifax Neuropituitary (HNP) and Capital Health Outpatient Clinics databases. A retrospective analysis was carried out on all patients with SM and included any of the following diagnoses: nonfunctioning pituitary adenoma (NFA), prolactinoma, growth hormone $(\mathrm{GH})$-secreting adenoma, adrenocorticotropic hormone (ACTH)-secreting adenoma, thyroidstimulating hormone (TSH)-secreting adenoma or any of the nonpituitary tumors including craniopharyngioma, Rathke's cleft cyst (RCC), pituitary cyst, meningiomas, or lipomas. The study was approved by the Capital Health Research Ethics Board.

\section{HNP Database}

The HNP clinic was initiated in 2000, whereas the database was first launched in November 2005; it currently contains data on more than 1600 patients. This computerized database prospectively collects demographic, clinical, hormonal, radiological, and surgical data (when applicable) on all patients older than age of 16 years with pituitary disorders. All children with SM younger than age 16 within the province are referred to pediatric endocrinology and/or neurosurgery (both solely located in Halifax). Together, these centers receive on average two referrals each year; these patients' care is subsequently transferred to the HNP clinic once they reach the age of 16 . Since November 2005, 13 children were referred for SM, and their data were included in the analysis. All patients at the HNP clinic are followed by a single team comprising an endocrinologist (SAI) and neurosurgeon (DBC) as well as specialized nurses from endocrinology and neurosurgery. Also, this registry collects data on all patients with SM seen by the endocrinology center in Cape Breton.

\section{Capital Health Outpatient Clinics Database}

This database was initiated in June 2009. A small percentage of patients with suspected pituitary disorders are being followed by other adult endocrinologists in the division of endocrinology at Dalhousie University (outside the HNP clinics). Between 2009 and 2013, 126 patients were seen outside the HNP clinic by all other endocrinologists and their charts were reviewed. Of these, only 31 patients had SM (21 had prolactinoma, four nonfunctioning adenoma, two cases of craniopharyngioma, and one case each of ACTH-secreting adenoma, RCC, hypophysitis, and pituitary sarcoidosis).

\section{Diagnostic Strategies for Pituitary-Related Growths}

Pituitary-related growths are generally referred to as pituitary adenomas (PAs). PAs were categorized based on their size into macroadenomas $(\geq 10 \mathrm{~mm})$ or microadenomas $(<10 \mathrm{~mm})$ and functional status into either NFA or functioning adenomas (FAs). FAs were further stratified based on the predominant hormonal release pattern as follows. A prolactinoma (PRLoma) was defined as FA associated with detectable PA on imaging, a persistently elevated prolactin level, and presence of symptoms related to high prolactin levels. A subgroup of patients without a detectable MRI lesion but persistently elevated prolactin and absence of secondary causes of hyperprolactinemia such as hypothyroidism, chronic kidney disease, hepatic cirrhosis, and medications known to raise prolactin were defined as MRI-negative PRLoma based on previously published analysis. ${ }^{6} \mathrm{GH}$-secreting adenomas were diagnosed on the basis of typical clinical features, an elevated age, and gender-matched serum insulin-like growth factor-1 and inability to suppress $\mathrm{GH}$ following a $75 \mathrm{~g}$ oral glucose load. ACTH-secreting adenomas were diagnosed based on clinical and biochemical features of hypercortisolism and evidence of pituitary origin of hypercortisolism based on some or all of the following tests: false normal or elevated ACTH, abnormal dexamethasone suppression test, adequate stimulation with a corticotropinreleasing hormone test, and inferior petrosal sinus sampling with or without a detectable pituitary tumor. TSH-secreting adenoma was diagnosed based on an elevated free T4, inappropriately normal or elevated TSH and presence of pituitary tumor, and a positive tissue diagnosis. NFA was diagnosed when there was no clinical and/or biochemical evidence of hormonal oversecretion and in cases of macroadenoma where serum prolactin was $<150 \mathrm{mcg} / \mathrm{L}(\mathrm{N}=2.1$ to 17.7 in males and 2.8 to 29.2 in females). For other sellar and parasellar tumors, the diagnosis was based on typical clinical and radiological features; the latter was judged either by an experienced neurosurgeon or directly obtained from the radiology report. For all patients who underwent surgery, tissue diagnosis was the primary method for making the diagnosis. Secondary hormone insufficiency was defined as follows. Adrenal insufficiency was defined as either basal serum cortisol of 
$<130 \mathrm{nmol} / 1$, failure of serum cortisol to rise $\geq 500 \mathrm{nmol} / 1$ after an insulin tolerance test, or $250 \mathrm{mcg}$ ACTH stimulation test based on our previously published data. ${ }^{13}$ Secondary hypothyroidism diagnosis was based on low free T4 with inappropriate normal or low TSH. Diabetes insipidus was diagnosed based on the presence of polyuria and polydipsia in addition to abnormal water deprivation test. We do not routinely perform dynamic testing for $\mathrm{GH}$ deficiency unless coverage for GH therapy is available; therefore, GH deficiency was defined as a low insulin-like growth factor-1.

\section{Study Population}

Nova Scotia is a major province in Atlantic Canada. The population of the province has remained relatively stable between 2000 and $2013(932,491$ to 945,061). Dalhousie University is the sole tertiary care facility for the province. It is centrally located and caters to patients from southern and central Nova Scotia, whereas Sydney, Cape Breton, which is the second largest health care facility in the province, provides secondary health care for northern Nova Scotia. All pituitary patients within the province are referred to either endocrinology (in Dalhousie University and Sydney) or neurosurgery (Dalhousie University).

\section{Data Analysis}

Population characteristics were summarized as means with standard deviation for continuous variables and frequencies with percentages for categorical data. Overall prevalence was calculated as the number of patients with diagnoses of SM divided by the Nova Scotia population according to census information provided by statistics Canada as of December 31, 2013. The World Health Organization 2000 standard population was used to compute standardized incidence rates (SIRs) in all SM as well as specific subtypes. Overall SIR was calculated using average yearly data in the period following the introduction of the HNP database. Incidence and prevalence rates are presented as per 100,000 per year unless otherwise stated. Differences between continuous variables were assessed using the Student $t$-test. Associations between categorical were analyzed using Fisher's exact test. All statistical comparisons were two-sided using a significance level of $\mathrm{p}=0.05$. Analyses were conducted in SAS, version 9.4 (Cary, NC).

\section{RESULTS}

\section{Frequency and Distribution of SM}

Between 2005 and 2013, 1107 patients were evaluated for clinically manifesting SM, of which 1005 were alive and residing within the province by December 1, 2013. Their characteristics are summarized in Table 1. Of those who were excluded, 59 had died, whereas 57 were residing outside the province. The mean age on presentation was $44.6 \pm 18$ years. The age distribution of various SM is shown in Figure 1. There were 624 (62\%) females and $381(38 \%)$ males, with an overall preponderance of females across most categories of SM. The rate of diagnosis of SM increased over time, with approximately 234 (23\%) being diagnosed before 2000, 235 (23\%) between 2000 and 2005, and 536 (53\%) diagnosed during the past 8 years (between 2006 and 2013). Of 1005 patients with SM, 838 (83\%) had PAs and 167 (17\%) had nonpituitary sellar lesions. The most common SMs were NFAs $(38.4 \%)$, followed closely by PRLoma $(34.3 \%)$.

\section{Table 1: Baseline characteristics}

\begin{tabular}{|c|c|}
\hline Total patients & 1005 \\
\hline Age: mean (SD) & 44.6 years $(17.7)$ \\
\hline \multicolumn{2}{|l|}{ Gender } \\
\hline Female, n (\%) & $624(62.1 \%)$ \\
\hline Male, n (\%) & $381(37.9 \%)$ \\
\hline \multicolumn{2}{|l|}{ Year of diagnosis, n (\%) } \\
\hline Pre-2000 & $234(23.3 \%)$ \\
\hline $2000-2005$ & $235(23.4 \%)$ \\
\hline 2006-2013 & $536(53.3 \%)$ \\
\hline \multicolumn{2}{|l|}{ Diagnosis, n (\%) } \\
\hline Nonfunctioning & $389(38.7 \%)$ \\
\hline Prolactinoma & $345(34.3 \%)$ \\
\hline $\mathrm{RCC}$ & $65(6.5 \%)$ \\
\hline GH-secreting adenoma & $65(6.5 \%)$ \\
\hline Craniopharyngioma & $45(4.5 \%)$ \\
\hline ACTH-secreting adenoma & $38(3.8 \%)$ \\
\hline Meningioma & $19(1.9 \%)$ \\
\hline Others & $39(3.9 \%)$ \\
\hline \multicolumn{2}{|l|}{ Tumor size category } \\
\hline Micro & $318(31.6 \%)$ \\
\hline Macro & $526(52.3 \%)$ \\
\hline MRI negative & $11(1.1 \%)$ \\
\hline Unknown & $150(14.9 \%)$ \\
\hline \multicolumn{2}{|l|}{ Family history } \\
\hline No & $665(66.2 \%)$ \\
\hline Yes & $30(3.0 \%)$ \\
\hline Unknown & $310(30.9 \%)$ \\
\hline
\end{tabular}

Based on the tumor size of all SMs at presentation, $526(52.3 \%)$ presented with masses $\geq 1 \mathrm{~cm}$ and $318(31.6 \%)<1 \mathrm{~cm}, 11(1.1 \%)$ had no discernible tumor, and no tumor size data were available in $150(14.9 \%)$. Of all patients, $665(66.2 \%)$ had no family history of SM in first-degree relatives, $30(3.0 \%)$ had a family history of SM in at least one first-degree relative; data were unavailable in 310 $(30.9 \%)$ patients.

SIRs of the most common SMs are shown in Table 2. The overall prevalence of all SM was around 107/100,000. There was a rapid rise in the SIRs after the launch of the database in November 2005; however, the SIRs have remained largely uniform since then, indicating stable capture of the data. When comparing the SIR trends of the two major subtypes of SM from before and after 2006, the yearly SIRs of NFA and PRLomas also remained stable.

\section{Clinical Presentation}

Details concerning features of the clinical presentation are discussed for each SM type. Of all patients, 230 presented as incidental pituitary lesions (prevalence/100,000 $=24.4$ ) and 66 presented with pituitary apoplexy (prevalence/100,000 =7.0). 
Among apoplexy patients, 48 presented with classical features of apoplexy, including severe headaches and visual abnormalities; 15 presented with visual abnormalities; and no information was available for the remaining three patients.

\section{Pituitary Dysfunction}

Hormonal profiles associated with various SM are summarized in Table 3. Of all SMs, hypophysitis and craniopharyngioma were more likely to be associated with pituitary dysfunction (75\% and

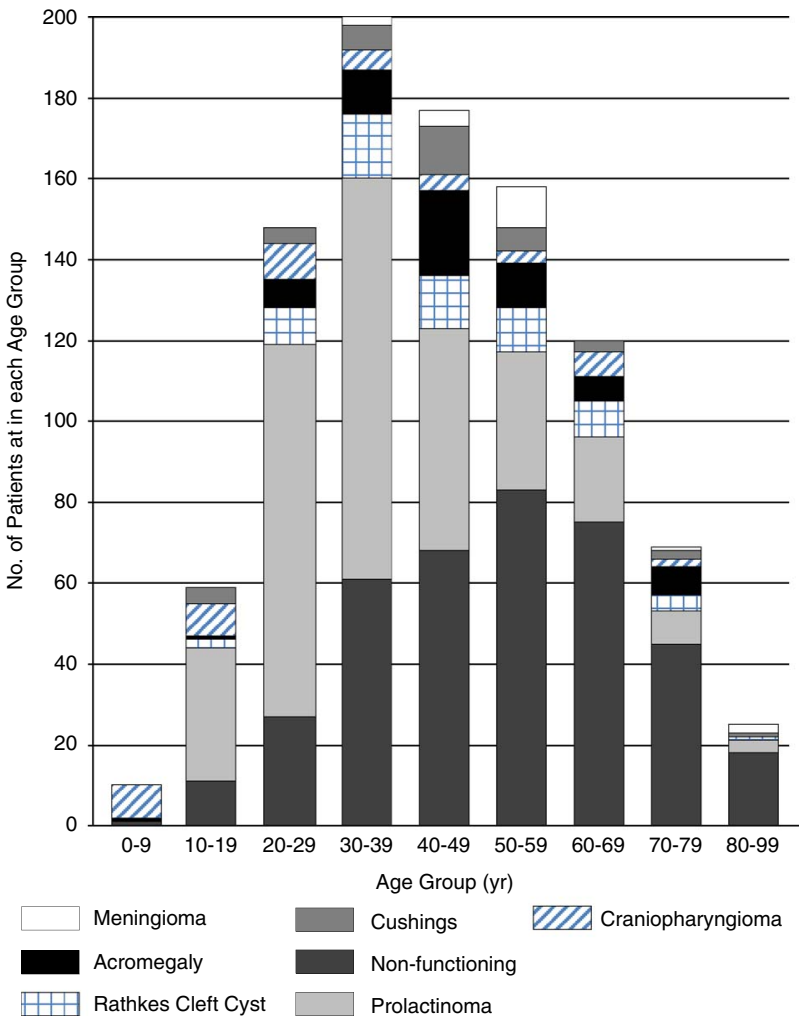

Figure 1: Age Distribution Of Various Sellar Masses.
$71.4 \%$, respectively). Various factors were associated with an increased risk of pituitary hormonal dysfunction in SMs, including: pituitary adenoma (odds ratio $=2.30 ; 1.47$ to 3.59 ), male gender $(2.92 ; 2.01$ to 4.11$)$, and tumors $\geq 10 \mathrm{~mm}$ at presentation, whereas the age at diagnosis and the length of follow-up did not increase the risk of pituitary dysfunction.

\section{Pituitary Adenomas}

\section{NFAs}

NFAs were the most frequent SMs, accounting for almost $39 \%$ of all SMs and $48 \%$ of PAs. The SIR of NFAs was 2.34 and prevalence was $41.34 / 100,000$. There were more women in the NFA group $(215 / 385 ; 55 \%)$ and the mean age of diagnosis was $52.1 \pm 16.8$ years. The mean age of presentation in women $(49.0 \pm 17.2$ years) was significantly lower than in men $(56 \pm 15.4$ years; $\mathrm{p}<0.0001)$. Of the 385 NFA patients in the HNP database, $269(70 \%)$ presented with macroadenomas, 93 (24\%) had microadenomas, and data were unavailable in $23(6 \%)$ patients. Presenting features were clearly identified in 323 (83\%) patients and the three most common modes of presentation were: incidental finding in $116(35 \%)$, headache in 108 (32\%), and vision loss in 93 (28\%). Biochemical data on the complete panel of hypothalamic-pituitary function on presentation were available in 251/385 (65\%) patients, of which 107 (43\%) had evidence of one or more pituitary axis dysfunction on presentation (see Table 3). The most common deficiency was secondary hypogonadism (34\%) followed by secondary hypothyroidism (24\%), whereas $11 \%$ presented with evidence of dysfunction of three or more axes. Overall, 208 (54\%) patients underwent surgical treatment, whereas the rest are being followed clinically.

\section{Prolactinomas}

PRLomas were the second most prevalent SMs (345/1005), constituting $41 \%$ of all PAs, which constituted $34 \%$ of all SMs. Prevalence and SIR were $36.67 / 100,000$ and 2.22 , respectively. There were more women $(242 / 345 ; 70 \%)$ in the PRLoma group than men $(103 / 345 ; 30 \%)$. The mean age at diagnosis was

Table 2: Incidence rate for the common sellar masses

\begin{tabular}{|c|c|c|c|c|c|c|c|c|}
\hline Year & SIR & NFA & PRLoma & Acromegaly & ACTH adenoma & Rathke's cyst & Craniopharyngioma & Meningioma \\
\hline 2000 & 2.57 & 1.07 & 0.96 & 0.08 & 0.00 & 0.08 & 0.37 & 0.00 \\
\hline 2001 & 3.86 & 1.34 & 1.38 & 0.29 & 0.17 & 0.55 & 0.00 & 0.00 \\
\hline 2002 & 3.73 & 0.95 & 1.63 & 0.36 & 0.26 & 0.32 & 0.22 & 0.00 \\
\hline 2003 & 3.78 & 1.05 & 1.97 & 0.28 & 0.07 & 0.10 & 0.14 & 0.00 \\
\hline 2004 & 3.78 & 1.37 & 1.61 & 0.28 & 0.08 & 0.16 & 0.13 & 0.08 \\
\hline 2005 & 4.89 & 1.91 & 2.08 & 0.15 & 0.24 & 0.30 & 0.00 & 0.08 \\
\hline 2006 & 6.52 & 2.45 & 3.19 & 0.20 & 0.07 & 0.07 & 0.33 & 0.08 \\
\hline 2007 & 4.43 & 2.00 & 1.29 & 0.37 & 0.14 & 0.14 & 0.29 & 0.11 \\
\hline 2008 & 5.46 & 2.17 & 1.71 & 0.33 & 0.25 & 0.55 & 0.11 & 0.08 \\
\hline 2009 & 7.34 & 2.95 & 2.12 & 0.21 & 0.27 & 0.49 & 0.26 & 0.28 \\
\hline 2010 & 6.62 & 2.08 & 2.86 & 0.13 & 0.21 & 0.60 & 0.14 & 0.12 \\
\hline 2011 & 6.64 & 2.13 & 2.59 & 0.31 & 0.06 & 1.07 & 0.12 & 0.05 \\
\hline 2012 & 5.91 & 2.55 & 2.20 & 0.35 & 0.06 & 0.32 & 0.18 & 0.12 \\
\hline 2013 & 6.25 & 2.35 & 1.83 & 0.38 & 0.29 & 0.72 & 0.06 & 0.19 \\
\hline
\end{tabular}


Table 3: Hormonal profile of the common sellar masses

\begin{tabular}{l|c|c|c|c|c|c|c}
\hline & & \multicolumn{5}{|c}{ Hormonal axis affected } \\
\hline Type of SM & Hormonal deficiencies & GH deficiency & Hypogonadism & Hypothyroidism & Adrenal Insufficiency & Diabetes Insipidus & 3 or more \\
\hline Nonfunctioning adenoma & $107 / 251(42.6 \%)$ & $35(13.9 \%)$ & $86(34.3 \%)$ & $60(23.9 \%)$ & $27(10.8 \%)$ & $3(1.2 \%)$ & $28(11.2 \%)$ \\
\hline Prolactinoma & $115 / 175(65.7 \%)$ & $19(10.9 \%)$ & $94(53.7 \%)$ & $29(16.6 \%)$ & $5(2.9 \%)$ & $0(0 \%)$ & $11(6.3 \%)$ \\
\hline GH adenoma & $15 / 37(40.5 \%)$ & $0(0 \%)$ & $12(32.4 \%)$ & $8(21.6 \%)$ & $1(2.7 \%)$ & $0(0 \%)$ & $1(2.7 \%)$ \\
\hline ACTH adenoma & $7 / 19(36.8 \%)$ & $0(0 \%)$ & $5(26.3 \%)$ & $4(21.1 \%)$ & $0(0 \%)$ & $0(0 \%)$ & $1(5.3 \%)$ \\
\hline RCC & $9 / 46(19.6 \%)$ & $1(2.2 \%)$ & $6(13 \%)$ & $7(15.2 \%)$ & $5(10.9 \%)$ & $0(0 \%)$ & $4(8.7 \%)$ \\
\hline Craniopharyngioma & $15 / 21(71.4 \%)$ & $7(33.3 \%)$ & $10(47.6 \%)$ & $9(42.9 \%)$ & $5(23.8 \%)$ & $2(9.5 \%)$ & $6(28.6 \%)$ \\
\hline Meningioma & $1 / 10(10 \%)$ & $0(0 \%)$ & $0(0 \%)$ & $1(10.0 \%)$ & $0(0 \%)$ & $0(0 \%)$ & $0(0 \%)$ \\
\hline
\end{tabular}

$37.0 \pm 14.9$ years, with $55.2 \%$ of all PRLomas diagnosed between the ages of 20 and 40 years. Data on tumor size at presentation were available in $281 / 345(81 \%)$ of patients, of which 163/281 (58.0\%) presented with microadenomas, 110/280 (39.1) \% had macroadenomas, and 8/281 (3\%) had no discernible adenoma on MRI. Gender difference was noted in tumor size in that $63 / 110(57.3 \%)$ of males presented with macroprolactinomas compared with only $31 / 163(19 \%)$ of females $(\mathrm{p}<0.0001)$. The most common presenting features in women were galactorrhea (41\%), amenorrhea (39\%), and menstrual irregularity $(17 \%)$, whereas in men these were decreased libido (37\%), headache (28\%), and incidental findings $(21 \%)$. Ninety-three percent of PRLoma patients were treated with medical therapy, whereas $7 \%$ had underwent surgery as the primary mode of treatment. Complete pituitary profile at presentation was available in $51 \%$ PRLoma patients, of which almost $66 \%$ had evidence of at least one hormonal axis deficiency at diagnosis with secondary hypogonadism being the most common deficiency in almost $54 \%$ patients (see Table 3 ).

\section{GH-Secreting Adenomas}

Following PRLoma, GH-secreting adenoma patients constituted the second most common functioning adenomas, constituting 7.8\% of PA and $6.5 \%$ of all SM, with a SIR of 0.3 and prevalence of $6.90 /$ 100,000 . The mean age at diagnosis was $46.8 \pm 15.0$ years. Females constituted $53 \%$ of $\mathrm{GH}$-secreting adenoma patients. At presentation, $44(68 \%)$ had macroadenoma, nine $(14 \%)$ had microadenoma, one $(0.01 \%)$ had no discernible tumor, and no data were available in $10(16 \%)$ patients. The most common presenting features included: enlarging shoe size (45\%), increasing ring size (26\%), and sweating (26\%). Complete hormonal profile at presentation was available in $37(58 \%)$ patients, of which $15(41 \%)$ had evidence of pituitary dysfunction (Table 3), with secondary hypogonadism being the most common hormonal deficiency $(32 \%)$, followed by secondary hypothyroidism (22\%); one patient had three or more hormonal deficiencies. The primary mode of therapy in patients with GH-secreting adenomas was surgery in 60 (94\%), whereas four $(6 \%)$ patients were initiated on medical therapy as the primary treatment.

\section{ACTH-Secreting Adenomas}

There were 38 patients with ACTH-secreting adenomas, which constituted $4.5 \%$ of all PAs. The overall prevalence was 4.03 / 100,000 and SIR was 0.2 . Women by far constituted the majority of the group $(30 / 38 ; 79 \%)$. The mean age at diagnosis was $43.5 \pm 16.5$ years. Tumor size data at presentation showed that $14(38 \%)$ had macroadenoma, eight $(21 \%)$ had microadenoma, two $(5 \%)$ had no discernible adenoma, and no data were available for $13(35 \%)$ patients. The most common clinical features at diagnosis were easy bruising (54.2\%), rapid weight gain (45.8\%), and proximal muscle weakness (37.5\%). A complete panel of pituitary function was available in $19(50 \%)$ patients, of which seven (37\%) presented with one or more hormonal insufficiencies - the most common being secondary hypogonadism in five (26\%), secondary hypothyroidism in four $(21 \%)$, and one patient had three or more insufficiencies. Pituitary surgery was the primary mode of therapy for all ACTH-secreting adenoma patients.

\section{Nonpituitary SMs \\ $\mathrm{RCC}$}

RCC was the most common nonpituitary SM (65/167), constituting $39 \%$ of all nonpituitary SMs and $6.5 \%$ of all SMs with a SIR of 0.5 and prevalence of $6.90 / 100,000$. Similar to most other SMs, there were more females $39(61 \%)$, and the mean age at diagnosis was $46.0 \pm 15.3$ years. The most common modes of presentation were incidental finding $(71 \%)$, headache $(28 \%)$, and vision abnormalities (12\%). One-third (32\%) of patients with RCC required surgery, whereas others are being followed conservatively. Tumor size at presentation was available in $58(89 \%)$ patients, of which 34 (59\%) were $\geq 1 \mathrm{~cm}$. Hormonal values on presentation were available in 46 (72\%), of which nine (20\%) had evidence of pituitary dysfunction: secondary hypothyroidism $(15 \%)$, secondary hypogonadism $(13 \%)$, and secondary hypoadrenalism $(11 \%)$. Three or more hormonal axes deficiencies were seen in four patients $(9 \%)$.

\section{Craniopharyngioma}

Forty-five patients ( $4.5 \%$ of all SMs) had craniopharyngiomas with a SIR of 0.2 and prevalence of $4.78 / 100,000$. The mean age of presentation was $31.6 \pm 22.1$ years, whereas eight patients presented before the age of 10 years. There were more men $(25 / 45 ; 55 \%)$ in this group; of the 27 patients whose tumor size on presentation was known, $22(81 \%)$ presented with tumor $\geq 10 \mathrm{~mm}$. The most common modes of presentation were headaches (44\%), vision abnormalities (41\%), and incidental finding $(33 \%)$ — and almost half $(53 \%)$ required surgery as primary therapy. Data on hormonal function at presentation were available in 
$21(47 \%)$ patients (see Table 3), of whom 15 (71\%) had evidence of pituitary hormonal dysfunction, with six (29\%) presenting with multiple hormonal deficiencies.

\section{Meningiomas}

Nineteen patients had sellar or parasellar meningiomas with prevalence of 2.01/100,000 and a SIR of 0.21. At presentation, 18 had tumors $\geq 1 \mathrm{~cm}$, whereas 1 was $<1 \mathrm{~cm}$. The most common modes of presentation were vision loss $(60 \%)$, incidental finding $(33 \%)$, and headache $(13.3 \%)$. Hormonal dysfunction data for meningioma are summarized in Table 3.

\section{“Other" Sellar Lesions}

Thirty-nine patients were categorized as having "other" lesions, with a total prevalence of 4.14/1000. These included: cystic pituitary lesions (16), hypophysitis (five), arachnoid cyst (five), histiocytosis (four), nonspecific hypothalamic lesions (three), atypical epithelial neoplasm (two), and one each of germinoma, TSH-secreting adenoma, plasmacytoma, and osteolipoma. There was no case of gonadotropin-secreting adenoma in our series. The overall SIR of these lesions was 0.13 . There were no cases of pituitary carcinoma in our study. Hormonal information in four of five patients with hypophysitis was available, of which three $(75 \%)$ had evidence of dysfunction. Two (50\%) had GH deficiency, one (25\%) had secondary hypogonadism, two $(50 \%)$ had secondary hypothyroidism, two (50\%) had secondary adrenal insufficiency, and two (50\%) had diabetes insipidus.

\section{DISCUSSION}

To our knowledge, this is the largest North American population-based study to evaluate the epidemiology of clinically manifesting pituitary and nonpituitary SM describing their incidence over a 7-year period. In this study, we report an overall prevalence of $0.1 \%$ for all SMs. PAs constituted the vast majority of SM in our study, with a prevalence and SIR of 82.2 and 5.0 per 100,000 , respectively. Our data are in agreement with the reported prevalence rates from Belgium, the United Kingdom, and Malta, which ranged between 75.7 and 94/100,0005,6,8 Concurrence with these reports suggests that the prevalence of PAs has been stable over the past decade and is similar across different geographic areas. Similarly, the incidence of PAs, although slightly higher in our study (5.0), is comparable with the previously reported incidence of 3.9 to 4.27 from other centers. ${ }^{3,8}$ However, the relative distribution of various subtypes of PAs was somewhat different in that, unlike other studies that reported PRLoma being the most common PA, ${ }^{2-6}$ our data showed that the most common subtype was NFA (38.7\%) followed by PRLoma (34.3\%). The prevalence and incidence rates of $\mathrm{GH}$-secreting adenomas, ACTH-secreting adenomas, and TSH-secreting adenomas were comparable to previous data. The overall SIR of incidental pituitary lesions in our study was 1.62 , which is comparable with other studies that have reported the incidence of 0.59 to $1.6 / 100,000 .^{3,6}$

Our study is unique in that we studied the epidemiology of all SMs. Of the nonpituitary SMs, RCC was the most common entity (6.5\% of all SMs) and where $71 \%$ of all RCCs were detected incidentally and most of them were $>1 \mathrm{~cm}$, would suggest that the actual prevalence of RCC may be even higher. A similar trend has been reported in other studies where RCC constitutes 18.6 to
$27.5 \%$ of incidental SMs, ${ }^{10-12}$ suggesting a much higher prevalence of RCC than what we have reported. Similar to RCC, craniopharyngiomas are benign, slow-growing SMs with an unknown prevalence but an incidence of 0.17 to $0.19 / 10,000$ based on the most recent studies. ${ }^{14,15}$ The prevalence of craniopharyngioma in our study was $4.8 / 100,000$ with a SIR of 0.2 . To our knowledge, this is the first study to evaluate the incidence of craniopharyngioma in a large population. Although intracranial meningiomas represent about one-third of all primary brain tumors, ${ }^{14}$ information regarding sellar/parasellar meningiomas is not widely available. This may at least in part be due to referral patterns and institutional practice in which meningiomas of the sellar/parasellar region may be seen and managed without referral to a pituitary service. In our experience, for example, only with the development of endoscopic transsphenoidal surgery (beginning in 2004) did we start to see patients referred for management of meningiomas. Therefore, one must be cautious when interpreting these data. Our data do show that the sellar/parasellar meningiomas referred to us were larger lesions and frequently associated with significant pituitary hormonal dysfunction. Our findings emphasize the need for comprehensive hormonal assessment at the time of diagnosis of sellar/parasellar meningiomas.

Although SM can affect patients of any age group, our study showed distinct association between certain age ranges and SM. A vast majority of patients presenting before the age of 10 had craniopharyngioma (64\%), whereas $51 \%$ within the age range of 10 to 39 years had PRLomas and $51 \%$ older than age 40 years had NFAs. This finding is expected given that craniopharyngiomas are derived from embryological remnants of the Rathke's pouch and, therefore, any related abnormality would likely present early in life. This is concordant with previously published data showing the peak incidence of craniopharyngioma in children between the ages of 5 and 9 years. ${ }^{12}$ Similarly, clustering of PRLomas within the reproductive age group of 20 to 40 years in our study is also in agreement with previous work. ${ }^{8}$

Hypopituitarism can occur in patients with SM depending on factors such as the size, type, and location of the tumor. Previously published studies have not consistently documented hormonal profiles of the patients presenting with SM and, to our knowledge, this study is the only one that has systematically assessed pituitary hormonal function in relation to various types of SMs. Our data showed a high risk of hypopituitarism, varying between different subtypes from $36.8 \%$ to $75 \%$, with the highest being in patients with hypophysitis or craniopharyngiomas. Almost $43 \%$ of our NFA patients had some degree of pituitary insufficiency. Previous studies have reported partial pituitary dysfunction rate of $61 \%$ in a select population of large NFA undergoing surgery ${ }^{16}$ and approximately $80 \%$ in large PRLoma. ${ }^{17}$

Diabetes insipidus is a rare complication of SM with an uncertain prevalence. In one study of 444 patients with pituitary tumors, nine (2\%)—of which six either had surgery or apoplexy—had diabetes insipidus. $^{18}$ Our study showed that only $1.2 \%$ of NFA patients presented with diabetes insipidus, whereas the highest risk of diabetes insipidus occurred in patients with hypophysitis (50\%) and craniopharyngiomas $(9.5 \%)$, findings that are consistent with previous studies reporting a high risk of diabetes insipidus in hypophysitis $(52 \%)$ and in childhood craniopharyngioma $(8 \%$ to $35 \%)$. ${ }^{19,20}$

Our study has several strengths. It is the largest North American study based on a stable provincial population. Furthermore, we have 
obtained comprehensive data from all centers, which has been prospectively collected during 8 years. A stable SIR over time further strengthens the comprehensiveness of our dataset. Additionally, we have reported the epidemiology on all SMs, unlike many previous studies that primarily focused on PAs alone. However, there are limitations to our study. Not all data in our study were prospectively collected; data collected before 2006 were obtained retrospectively through chart review, and some elements of the data were not consistently available. Additionally, the rates of GH deficiency in our cohort may not be accurate because we do not consistently perform dynamic testing for $\mathrm{GH}$ deficiency. Unlike other hormone replacement, the cost of GH therapy is not routinely covered by provincial health insurance; therefore, we reserve dynamic testing only for select patients who are granted provincial coverage or who have private coverage for $\mathrm{GH}$ therapy.

\section{Conclusions}

The epidemiology of SMs in our study, the largest series from North America, shows a prevalence of $0.1 \%$ and a stable SIR of 6.15. Our data also show distinct age and gender distributions of these lesions and a high risk of associated pituitary dysfunction. More studies are needed to evaluate SMs' natural history and help allocate appropriate resources to their management.

\section{Disclosures}

None of the authors has anything to disclose.

\section{REFERENCES}

1. Dolecek TA, Propp JM, Stroup NE, et al. CBTRUS statistical report: primary brain and central nervous system tumours diagnosed in the United States in 2005-2009. Neuro Oncol. 2012;14(Suppl 5):1-49.

2. Shibui S. The present status and trend of brain tumours based on the data of the Brain Tumor Registry of Japan. Brain Nerve. 2012;64:286-90.

3. Raappana A, Koivukangas J, Ebeling T, et al. Incidence of pituitary adenomas in Northern Finland in 1992-2007. J Clin Endocrinol Metab. 2010;95:4268-75.

4. Tjörnstrand A, Gunnarsson K, Evert M, et al. The incidence rate of pituitary adenomas in western Sweden for the period 2001-2011. Eur J Endocrinol. 2014;171:519-26.
5. Daly AF, Rixhon M, Adam C, et al. High prevalence of pituitary adenomas: a cross-sectional study in the province of Liege, Belgium. J Clin Endocrinol Metab. 2006;91:4769-75.

6. Fernandez A, Karavitaki N, Wass JA. Prevalence of pituitary adenomas: a community-based, cross-sectional study in Banbury (Oxfordshire, UK). Clin Endocrinol. 2010;72:377-82.

7. Fontana E, Gaillard R. Epidemiology of pituitary adenoma: results of the first Swiss study. Rev Med Suisse. 2009;5:2172-4.

8. Gruppetta M, Merciera C, Vassallo J. Prevalence and incidence of pituitary adenomas: a population based study in Malta. Pituitary. 2013;16:545-53.

9. McDowell BD, Wallace RB, Carnahan RM, et al. Demographic differences in incidence for pituitary adenoma. Pituitary. 2011;14:23-30

10. Lee YJ, Cho SW, Kim SW, et al. Characteristics and natural course of pituitary incidentalomas in Korea. J Korean Endo Soc. 2008; 22:111-6.

11. Sanno M, Oyama K, Tahara S, et al. A survey of pituitary incidentalomas in Japan. Eur J Endocrinol. 2003;149:123-7.

12. Scangas GA, Laws ER Jr. Pituitary incidentalomas. Pituitary. 2014; 17:486-91.

13. Yip CE, Stewart SA, Imran F, et al. The role of morning basal serum cortisol in assessment of hypothalamic-pituitary-adrenal axis. Clin Invest Med. 2013;36:E216-22.

14. Zacharia BE, Bruce SS, Goldstein $\mathrm{H}$, et al. Incidence, treatment and survival of patients with craniopharyngioma in the surveillance, epidemiology and end results program. Neuro Oncol. 2012; 14:1070-8.

15. Nielson EH, Jorgensen JO, Bierre P, et al. Acute presentation of craniopharyngioma in children and adults in a national Danish Cohort. Pituitary. 2013;16:528-35.

16. Chen L, White WL, Spetzler RF, et al. A prospective study of nonfunctioning pituitary adenomas: presentation, management, and clinical outcome. J Neurooncol. 2011;102:129-38.

17. Colao A, Sarno AD, Cappabianca P, et al. Gender differences in the prevalence, clinical features and response to cabergoline in hyperprolactinemia. Eur J Endocrinol. 2003;148:325-31.

18. Fatemi N, Dusick JG, Mattozo C, et al. Pituitary hormonal loss and recovery after transsphenoidal adenoma removal. Neurosurgery. 2008;63:709-19.

19. Imber BS, Lee HS, Kunwar S, et al. Hypophysitis: a single center case series. Pituitary. 2015;18:630-41.

20. Ghirardello S, Garre ML, Rossi A, et al. Diabetes insipidus in craniopharyngioma: postoperative management of water and electrolyte disorders. J Paediatr Endocrinol Metab. 2006; $1: 413-21$. 